EXTENDED REPORT

\title{
Expression and activity of citrullinating peptidylarginine deiminase enzymes in monocytes and macrophages
}

\author{
E R Vossenaar, T R D Radstake, A van der Heijden, M A M van Mansum, C Dieteren, D-J de Rooij, \\ P Barrera, A J W Zendman, W J van Venrooij
}

Ann Rheum Dis 2004;63:373-381. doi: 10.1136/ard.2003.012211

See end of article for
authors' affiliations
......................
Correspondence to:
Dr E R Vossenaar, 161
Department of
Biochemistry, PO Box
9101,6500 HB Nijmegen,
The Netherlands;
e.vossenaar@ncmls.kun.nl
Accepted
9 September 2003
........................

\begin{abstract}
Background: Antibodies directed to proteins containing the non-standard amino acid citrulline, are extremely specific for rheumatoid arthritis (RA). Peptidylcitrulline can be generated by post-translational conversion of arginine residues. This process, citrullination, is catalysed by a group of calcium dependent peptidylarginine deiminase (PAD) enzymes.

Objective: To investigate the expression and activity of four isotypes of PAD in peripheral blood and synovial fluid cells of patients with RA.

Results: The data presented here show that citrullination of proteins by PAD enzymes is a process regulated at three levels: transcription-in peripheral blood PAD2 and PAD4 mRNAs are expressed predominantly in monocytes; PAD4 mRNA is not detectable in macrophages, translation-translation of PAD2 mRNA is subject to differentiation stage-specific regulation by its $3^{\prime}$ UTR, and activation-the PAD proteins are only activated when sufficient $\mathrm{Ca}^{2+}$ is available. Such high $\mathrm{Ca}^{2+}$ concentrations are normally not present in living cells. In macrophages, which are abundant in the inflamed RA synovium, vimentin is specifically citrullinated after $\mathrm{Ca}^{2+}$ influx.

Conclusion: PAD2 and PAD4 are the most likely candidate PAD isotypes for the citrullination of synovial proteins in RA. Our results indicate that citrullinated vimentin is a candidate autoantigen in RA.
\end{abstract}

$\mathrm{T}$ he blood of patients with rheumatoid arthritis (RA) contains large numbers of circulating antibodies directed against a variety of autoantigens. The most widely known are the rheumatoid factor (RF), antibodies directed against the Fc part of IgG molecules (reviewed by Mageed ${ }^{1}$ ). RF can be detected in roughly $75 \%$ of patients with RA, but is also present in patients with other rheumatic or inflammatory diseases and even in a substantial percentage of the healthy (elderly) population. ${ }^{2}$ Its specificity for RA is thus limited.

Autoantibodies directed against citrullinated proteins have a much higher specificity for RA (reviewed by van Boekel et $\left.a l^{3}\right)$. This family of autoantibodies comprises the antiperinuclear factor," the so-called "antikeratin" antibodies," antifilaggrin antibodies, ${ }^{67}$ and anti-cyclic citrullinated peptide (anti-CCP) antibodies. ${ }^{8} 9$ These autoantibodies all recognise epitopes containing the non-standard amino acid citrulline; the naming of the antibody is simply determined by the method used to detect them. With the most sensitive assay (CCP2), anticitrullinated protein antibodies can be detected in almost $80 \%$ of RA sera with a specificity of $98 \% .^{3}{ }^{9-11}$ Besides being very specific for RA, ${ }^{9}{ }^{10} 1213$ anti-CCP antibodies can be detected very early in the disease and can predict clinical disease outcome, ${ }^{14-17}$ making them a useful tool for the clinician.

The relative amounts of anticitrullinated protein antibodies in synovial fluid (SF) and in extracts of synovial tissue of patients with RA is 1.4- and 7.5-fold higher, respectively, than in sera of the same patients. ${ }^{18} 19$ Furthermore, anticitrullinated protein antibody secreting cells are found in the inflamed RA synovia. ${ }^{19}{ }^{20}$ These data suggest the presence of citrullinated proteins in the RA synovium causing an antigen driven maturation of CCP-specific B cells at the site of inflammation. Indeed, the presence of citrullinated proteins in the RA synovium (for example, fibrin) has already been reported..$^{21}$
Because citrulline is a non-standard amino acid, it is not incorporated into proteins during translation. It can, however, be generated by post-translational enzymatic deimination (citrullination) of arginine residues..$^{22}$ This conversion is catalysed by the enzyme peptidylarginine deiminase (PAD, EC 3.5.3.15). Therefore, when citrullinated proteins are present in the inflamed RA synovium, ${ }^{21}$ PAD enzymes must also be present. Several isotypes of PAD exist, each with a different tissue distribution (reviewed by Vossenaar et $a l^{23}$ ). PADl and PAD3 are mainly found in epidermis and hair follicles. ${ }^{24-27}$ PAD2 is expressed in a variety of tissues, including muscle, brain, and haematopoietic cells, ${ }^{28-30}$ whereas the human PAD4 (formerly known as PAD5) is found primarily in haematopoietic cells. ${ }^{31-33}$

The RA synovial membrane contains large numbers of activated macrophages ${ }^{34}$; cells that have been described as expressing PAD enzymes and, under certain conditions, containing citrullinated proteins. ${ }^{35}{ }^{36}$ This makes them good candidates for the generation of synovial citrullinated antigens.

Here we describe the mRNA and protein expression of PAD enzymes in monocytes and macrophages, as well as in synovial fluid mononuclear cells (SFMCs). Possible mechanisms for regulation of $\mathrm{PAD}$ expression and activity are discussed.

\footnotetext{
Abbreviations: $A C R$, American College of Rheumatology; anti-MC anti-modified citrulline antibodies; CCP, cyclic citrullinated peptide; HUGO, human genome organisation; NP-40, Nonidet P40; PAD, peptidylarginine deiminase; $\mathrm{PB}$, peripheral blood; $\mathrm{PBMCs}$, peripheral blood mononuclear cells; PMCA, plasma membrane $\mathrm{Ca}^{2+}$ pump; RA, rheumatoid arthritis; RT-PCR, reverse transcriptase-polymerase chain reaction; SDS-PAGE, sodium dodecyl sulphate-polyacrylamide gel electrophoresis; SF, synovial fluid; SFMCs, synovial fluid mononuclear cells; UTR, untranslated terminal region
} 


\section{MATERIALS AND METHODS}

\section{Patients and controls}

Blood samples from patients matching the American College of Rheumatology (ACR) criteria for $\mathrm{RA}^{37}$ were collected with informed consent from the Department of Rheumatology of the University Medical Centre, St Radboud in Nijmegen. Paired samples of SF and peripheral blood (PB) from patients matching the ACR criteria for $\mathrm{RA}^{37}$ were collected with informed consent from the Department of Rheumatology of the Sint Maartenskliniek in Nijmegen. Blood samples from healthy people were collected from volunteering blood donors. All blood and SF samples were processed immediately to ensure optimal cell preparations.

\section{Cell isolation, culture, and calcium treatment}

Heparinised blood (15 ml) was diluted 1:1 with phosphate buffered saline (PBS) citrate (PBS containing $0.455 \% \mathrm{Na}_{3}$ citrate) and layered over a $15 \mathrm{ml}$ Ficoll cushion. After centrifugation for 20 minutes at $500 \mathrm{~g}$, the peripheral blood mononuclear cell (PBMC) containing interphase was collected and washed two times with PBS citrate. From here on PBMCs were fractionated either by plastic adherence, or with MACS magnetic beads (Miltenyi Biotec). For MACS fractionation, beads coated with either anti-CD3, anti-CD14, antiCD19, or anti-CD56 antibodies were used according to the manufacturer's instructions. For plastic adherence, PBMCs were cultured for 60 minutes in RPMI-1640 medium (with glutamax-I, Dutch modification, Gibco BRL) containing 10\% pooled human serum, $1 \mathrm{mM}$ pyruvate, and $50 \mu \mathrm{g} / \mathrm{ml}$ gentamicin (Gibco BRL) in six well culture plates, allowing monocytes to adhere to the plastic. The non-adherent lymphocytes were removed by washing the culture plates with PBS, after which the adherent monocytes were either harvested directly or allowed to differentiate into macrophages in seven days. This combined Ficoll centrifugation/ plastic adherence protocol allows for $>90 \%$ pure cell preparations. ${ }^{38}$ Mononuclear cells from SF were isolated by the same procedure. To increase cytosolic $\mathrm{Ca}^{2+}$ concentrations, cells were treated with either $1 \mu \mathrm{M}$ ionomycin (Sigma) or $1 \mu \mathrm{M}$ thapsigargin (Sigma) in Locke's solution ( $150 \mathrm{mM}$ $\mathrm{NaCl}, 5 \mathrm{mM} \mathrm{KCl}, 10 \mathrm{mM}$ Hepes. $\mathrm{KOH}$ pH 7.3, 0.1\% glucose) in the presence of $2 \mathrm{mM}$ extracellular calcium for 15 minutes up to 18 hours.

\section{Reverse transcriptase-polymerase chain reaction (RT-PCR)}

RNA was isolated from cells using Trizol reagent (Gibco BRL) according to the manufacturer's instructions. Synthesis of cDNA from $1 \mu \mathrm{g}$ of RNA was performed using the reverse transcription system (Promega) with $500 \mathrm{ng}$ of random primers. The reaction mixture was incubated for 10 minutes at room temperature, followed by 90 minutes at $42^{\circ} \mathrm{C}$. After incubation, cDNA samples were diluted with distilled water to $100 \mu \mathrm{l}$. For RT-PCR $10 \mu \mathrm{l}$ cDNA was added to $40 \mu \mathrm{l}$ mastermix containing $75 \mathrm{mM}$ Tris.Cl pH 8.8, $20 \mathrm{mM} \quad\left(\mathrm{NH}_{4}\right)_{2} \mathrm{SO}_{4}, \quad 0.01 \%$ ( $\mathrm{vol} / \mathrm{vol}$ ) Tween-20, $2 \mathrm{mM} \mathrm{MgCl}_{2}, 0.2 \mathrm{mM}$ dNTPs, $0.5 \mu \mathrm{M}$ forward and reverse primer, and $1 \mathrm{U}$ Red Hot DNA polymerase (ABGene). PCR was performed using a T3 thermocycler (Biometra): two minutes at $94^{\circ} \mathrm{C}, 25-35$ cycles of $\left(30 \mathrm{~s}, 94^{\circ} \mathrm{C} ; 30 \mathrm{~s}, 56-60^{\circ} \mathrm{C} ; 15-30 \mathrm{~s}, 72^{\circ} \mathrm{C}\right)$, two minutes at $72^{\circ} \mathrm{C}$. PCR product $(15 \mu \mathrm{l})$ was analysed on a $1.5 \%$ agarose gel using the Geldoc (Biorad) system. The following primer pairs were used (the size of the amplicon is given in parentheses): $\beta$-actin (239 bp) $5^{\prime}$-ACTCCATCATGAAGTGTGACG-3' and 5'-CATACTCCTGCTTGCTGATCC-3'; PADl (458 bp) 5'CCACAGCTGGCTGATG-3' and 5' -TCTCATTGGAGCCATGAG-3'; PAD2 (173 bp) 5'-CATGTCCCAGATGATCCTGC-3' and
5'-CATGGTAGAGCTTCCGCC-3'; PAD3 (314 bp) 5'

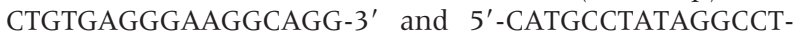
CACAC-3'; PAD4 (377 bp) 5'-GGACTGCGAGGATGATG-3' and $5^{\prime}$-GCTGTCTTGGAACACCAC-3'; $\alpha_{2}$-macroglobulin (147 bp), 5'-CAGCAGCAACCATGTCTTG-3' and 5'-TGCAAACTCATCCGTCTCG-3'. Cloned cDNAs served as positive control.

\section{Antibodies}

Rabbit antibodies directed against chemically modified citrulline (anti-MC) were a kind gift from Dr $\mathrm{T}$ Senshu (Tokyo, Japan). Mouse monoclonal antibodies against vimentin (RV202) were a kind gift from Dr F Ramaekers (Maastricht, The Netherlands).

Isotype-specific antibodies directed against PAD types 2 or 4 were produced by immunisation of rabbits with PAD isotype-specific peptides (PAD2: aa 3-8 and aa 516-531; PAD4: aa 210-225 and aa 517-531) (Eurogentec, Seraing, Belgium).

To affinity purify the anti-PAD antisera, $1 \mathrm{mg}$ of each of two peptides was conjugated to $8 \mathrm{mg}$ bovine serum albumin in the presence of $0.05 \%$ glutaraldehyde. After one hour at room temperature the reaction was stopped by adding 0.1 volume of $1 \mathrm{M}$ glycine. $\mathrm{NaOH} \mathrm{pH}$ 7.2. The mixture was dialysed against coupling buffer $\left(0.1 \mathrm{M} \mathrm{NaHCO} \mathrm{NH}_{3}\right.$ 8.3, $500 \mathrm{mM} \mathrm{NaCl}$ ) and then coupled to $0.5 \mathrm{~g} \mathrm{CNBr}$ activated Sepharose-4B (Amersham-Pharmacia) according to the manufacturer's instructions. The column was equilibrated in washing buffer (PBS pH 7.4, $350 \mathrm{mM} \mathrm{NaCl}, 0.05 \%$ Nonidet P40 (NP-40)) before serum was added. Unbound antibodies were removed by extensive washing. Anti-PAD antibodies were eluted with buffer (100 mM glycine. $\mathrm{HCl}$ pH 2.5, $500 \mathrm{mM} \mathrm{NaCl}, 0.05 \% \mathrm{NP}-40)$. Collected fractions were neutralised with $1 \mathrm{M}$ Tris $(\sim \mathrm{pH} 11)$.

\section{Western blot analysis}

Cells were washed with PBS and subsequently scraped in ice cold $50 \mathrm{mM}$ Tris. $\mathrm{HCl} \mathrm{pH} 7.4,100 \mathrm{mM} \mathrm{KCl}, 20 \mathrm{mM}$ ethylene glycol bis( $\beta$-aminoethylether)- $N, N^{\prime}$-tetraacetic acid (EGTA), $1 \mathrm{mM}$ dithioerythritol, 1\% NP-40, $0.5 \mathrm{mM}$ phenylmethylsulphonyl fluoride and Complete protease inhibitor cocktail (Roche). Extracts were sonified three times for 15 seconds with a microtip sonifier (Branson) at $20 \%$ output. For detection of PAD enzymes, extracts were centrifuged at $12000 \mathrm{~g}$ for 15 minutes. Soluble proteins were separated by sodium dodecyl sulphate-polyacrylamide gel electrophoresis (SDS-PAGE; 10\%) and transferred to nitrocellulose membranes. For detection of citrullinated proteins, extracts were concentrated by acetone precipitation before separation by SDS-PAGE (13\%) and transferred to Hybond-C extra (Amersham) membranes. Blots used to detect citrullinated proteins were chemically modified before immunostaining with anti-MC antibodies as described by Senshu et al. ${ }^{39}$ Blots were blocked in blocking buffer (PBS containing 5\% non-fat dried milk and $0.1 \% \mathrm{NP}-40$ ) for one hour at room temperature and incubated for one to three hours with the antibody of interest diluted in blocking buffer. After washing with blocking buffer, bound antibodies were detected by incubation with horseradish peroxidase conjugated swine antirabbit IgG antibodies (DAKO), followed by chemiluminescence. Purified recombinant His-tagged human PAD2 or PAD4 (a gift from S Nijenhuis, Nijmegen, The Netherlands) or in vitro citrullinated human fibrinogen served as a positive control.

\section{Immunoprecipitations of citrullinated vimentin}

For each immunoprecipitation $85 \mu \mathrm{l}$ mouse antivimentin (RV202) was coupled to $20 \mu \mathrm{l}$ of a $50 \%$ suspension of protein G-agarose beads in IPP $_{500}(500 \mathrm{mM} \mathrm{NaCl}, 10 \mathrm{mM}$ Tris.Cl $\mathrm{pH} 8.0,0.05 \%$ NP-40) for two hours at room temperature. 
Beads were washed three times with $\mathrm{IPP}_{500}$ and once with ice cold $\mathrm{IPP}_{150}(150 \mathrm{mM} \mathrm{NaCl}, 10 \mathrm{mM}$ Tris.Cl pH 8.0, 0.05\% NP-40). Extracts of ex vivo differentiated macrophages (prepared as described above) were added and the mixture was incubated for two hours at $4^{\circ} \mathrm{C}$. After three washes with $\mathrm{IPP}_{150}$, bound proteins were eluted with SDS-sample buffer, separated by SDS-PAGE (13\%), and transferred to Hybond-C extra (Amersham) membranes. The blots were stained with anti-MC antibodies to show the presence of citrullinated vimentin.

\section{UTR reporter study}

Human PAD2 cDNA (KIAA0994, AB023211, described by Kikuno et $a l^{40}$ ) was obtained from Kazusa DNA Research Institute, Japan. The 3' untranslated terminal region (UTR) sequence was subcloned by PCR into the XbaI site of the pGL3-promotor vector (Promega). In six well culture plates, $0.4 \times 10^{6}$ COS- 1 cells were seeded per well and transfected with $1 \mu \mathrm{g}$ of both plasmids, pGL3-promotor (either with or without PAD2 3' UTR sequence) plasmid DNA and pG5luc reporter vector (Promega), using $5 \mu \mathrm{l}$ Fugene transfection reagent (Roche), as described by the manufacturer. After 40 48 hours of growth, cells were harvested using $500 \mu \mathrm{l}$ Passive Lysis Buffer (PLB; Promega) and the activity of both the firefly luciferase and the control renilla luciferase was determined by the Dual Luciferase Reporter Assay System (Promega) on a Berthold Lumat LB 9507 luminometer. In brief, $100 \mu \mathrm{l}$ of firefly luciferase substrate solution was added to $20 \mu \mathrm{l}$ of cell extract and the luminescence was measured to determine the efficiency of the interaction. Next, $100 \mu \mathrm{l}$ of renilla luciferase substrate solution (containing a quencher for the firefly luciferase activity) was added and again the luminescence was determined to monitor the transfection efficiency. Results are expressed as the ratio of firefly versus renilla luciferase activity (mean (SD)).

\section{RESULTS}

\section{PAD type 2 and type 4 mRNAs are expressed in CD 14} positive cells

Mononuclear leucocytes are important in the pathology of RA. We investigated the expression of four isotypes of PAD in mononuclear blood cells. Total PBMCs were isolated from a healthy person by Ficoll density gradient centrifugation. Subsequently cells were subdivided with antibody coated magnetic beads into $\mathrm{T}$ cell $(\mathrm{CD} 3+), \mathrm{B}$ cell (CD19+), monocyte (CD14+), and NK cell (CD56+) fractions. Total RNA was isolated from the cells and each isotype of PAD was amplified by RT-PCR using PAD isotypespecific primers. Human PADl is mainly expressed in epidermis and uterus ${ }^{24}{ }^{27}$; PAD3 expression is restricted to hair follicles. ${ }^{26}$ It is therefore not surprising that PADI and PAD3 were undetectable in the PBMCs (fig 1). Human PAD2 is expressed in a broad range of tissues, including skeletal muscle, uterus, brain, salivary glands, and pancreas. ${ }^{23}$ Human PAD4 is found in haematopoietic cells. ${ }^{23}$ PAD2 and PAD4 mRNA could both be detected in the PBMCs. The vast majority of the expression was found in the CD3-, CD19-, CD56- and CD14+ fractions. PAD2 and PAD4 mRNA are thus predominantly expressed by CDl4 positive cells (fig 1, indicated by white squares).

\section{Differential expression of PAD during monocyte to macrophage differentiation}

To investigate the PAD2 and PAD4 expression by CD14+ cells in more detail, peripheral blood monocytes were differentiated into macrophages. Total PBMCs were isolated from the peripheral blood of patients with RA and healthy controls by Ficoll density gradient centrifugation. Monocytes were isolated by adherence to plastic six well culture plates.

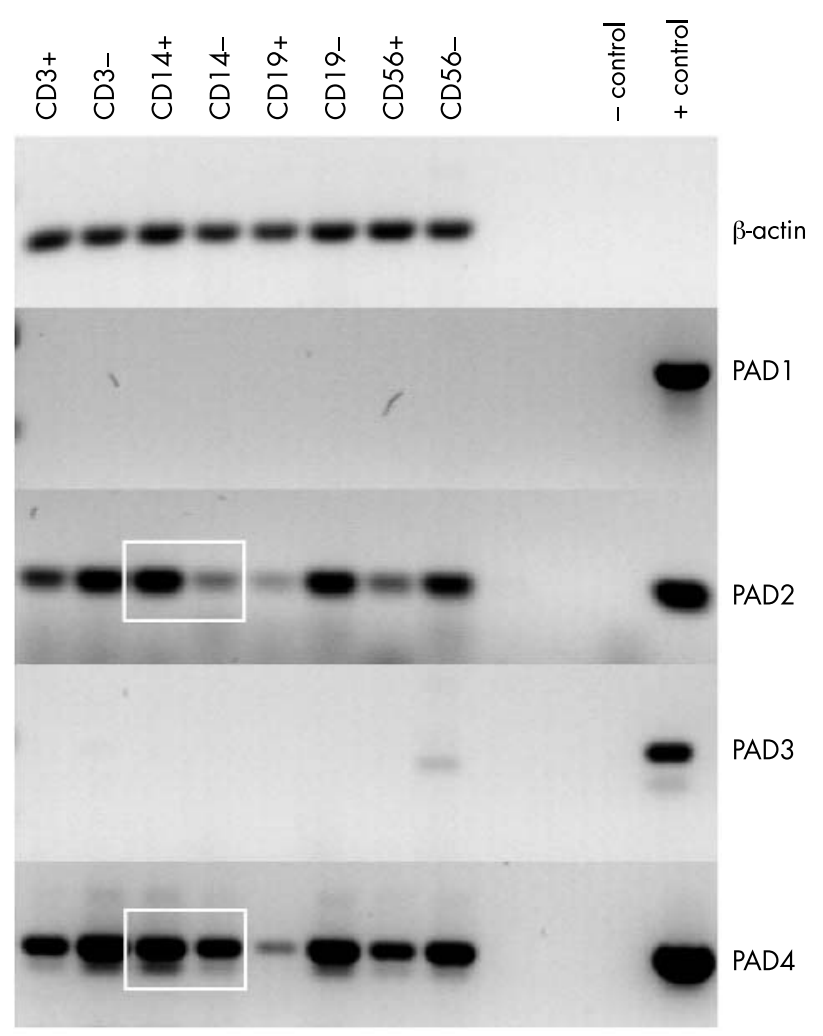

Figure 1 Messenger RNA expression of PAD isotypes in PBMCs. Total PBMCs from a healthy person were fractionated with MACS magnetic beads coated with either anti-CD3 (T cells), anti-CD14 (monocytes), antiCD19 ( $B$ cells) or anti-CD56 (NK cells) for RNA isolation. Expression of PAD was analysed by RT-PCR. PADI and 3 were not detectable in any of the PBMC fractions. For PAD2 and PAD4, specific PCR products were produced in all fractions. In the case of CD3, CD19, and CD56, the cells that did not bind to the beads (CD3- CD19-, CD56-) showed higher expression than the cells that did bind (CD3+, CD19+, CD56+). In contrast, the cells that were bound by the anti-CD14 coated beads (CD14+, monocytes) showed higher PAD2 and PAD4 expression than the cells that did not bind the anti-CD14 coated beads (CD14-, all but the monocytes) as indicated by white squares. $\beta$-Actin served as a control for mRNA input. Cloned cDNAs served as positive PCR controls, (no positive control included for $\beta$-actin), PCR without template as negative control.

After removal of non-adherent cells, the monocytes were differentiated into macrophages in seven days. PAD mRNA expression was evaluated by RT-PCR. Human PAD2 mRNA could be detected in equal amounts in monocytes and in macrophages (fig 2). No significant up or down regulation was observed during monocyte differentiation. PAD4 mRNA, however, could only be seen in the monocytes. The PAD4 mRNA expression was lost during differentiation (fig 2). Cells from patients with RA and healthy controls showed identical expression patterns.

The same cells were also tested for PAD protein expression. Protein extracts were analysed by immunoblotting using PAD isotype-specific antibodies. Surprisingly, PAD2 protein was only present in macrophages. Although PAD2 mRNA was equally expressed in monocytes and macrophages, very little (if any) PAD2 protein could be detected in the monocytes (fig 3). These results indicate that the differential expression of PAD2 is regulated at the translational level. PAD4 protein was detected at similar levels in monocytes and macrophages (fig 3). It appears that, although the message for PAD4 is gradually lost during the differentiation, the PAD4 protein level remains stable during the seven days of differentiation. Again, cells from patients 


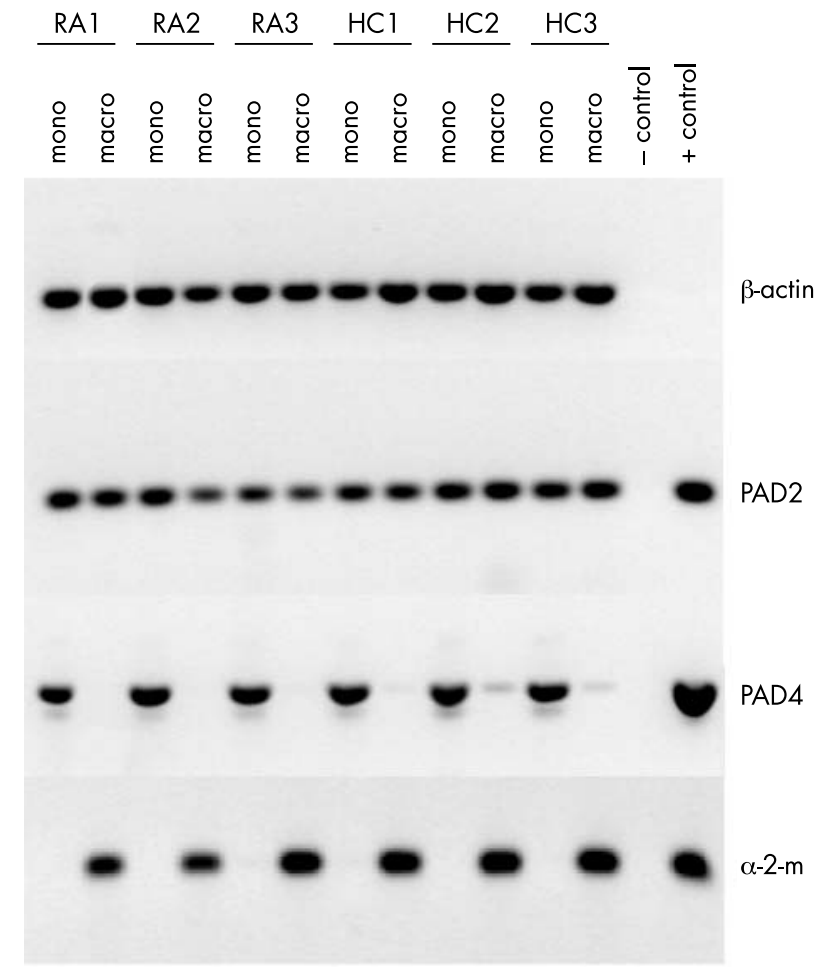

Figure 2 PAD4 mRNA is only expressed in monocytes, not in macrophages. RNA expression of PAD2 and PAD4 in freshly isolated monocytes (mono) from peripheral blood and in ex vivo differentiated macrophages (macro) of patients with RA (RA1-RA3) and healthy controls $(\mathrm{HCl}-\mathrm{HC} 3)$ was analysed by RT-PCR. $\beta$-Actin served as a control for mRNA input, $\alpha_{2}$-macroglobulin $(\alpha-2-m)$ expression was analysed as a control for macrophage differentiation. Cloned cDNAs served as positive PCR controls, (no positive control included for $\beta$-actin), PCR without template as negative control.

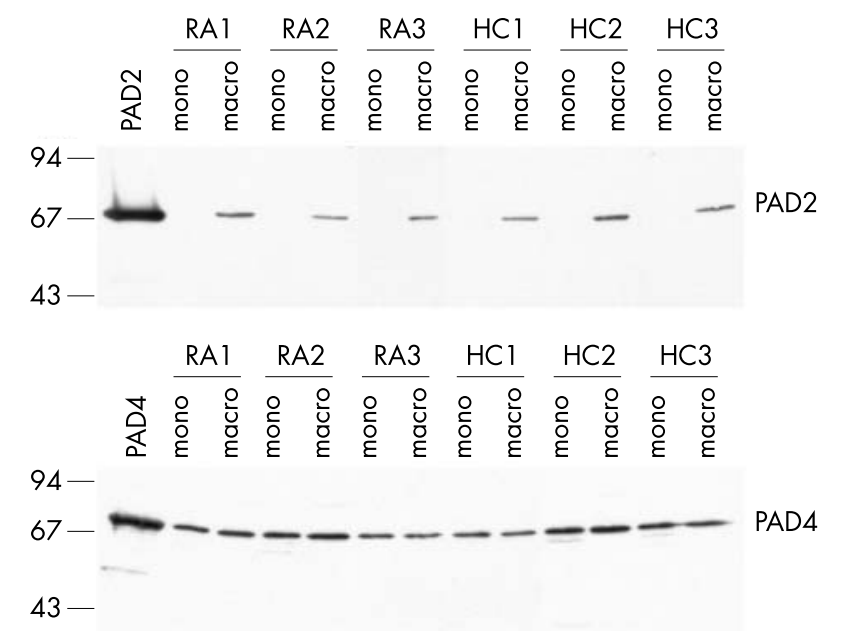

Figure 3 PAD2 protein is only expressed in macrophages. Protein expression of PAD2 and PAD4 in freshly isolated monocytes (mono) from peripheral blood and in ex vivo differentiated macrophages (macro) of patients with RA (RA1-RA3) and healthy controls ( $\mathrm{HCl}-\mathrm{HC} 3$ ) was analysed by western blotting. Recombinant PAD2 or PAD4 proteins are included as controls. Molecular weight markers $(\mathrm{kDa})$ are indicated on the left. with RA and healthy controls showed identical patterns of expression.

\section{Differential expression of PAD during monocyte infiltration into the joint}

The macrophages used in the previous experiments were differentiated ex vivo from circulating monocytes. Monocytes that infiltrate the synovium during inflammation will also differentiate into macrophages, albeit in an inflammatory environment. The differences between ex vivo and in vivo environments could induce subtle differences in the resulting phenotype of the macrophages. We therefore compared PAD expression in PMBCs and SFMCs of patients with RA. Mononuclear cells were isolated by Ficoll density gradient centrifugation from paired PB and SF samples. Total RNA was isolated for RT-PCR analysis, protein extracts were prepared for immunoblotting analysis.

PAD2 mRNA could be detected in equal amounts in PBMCs and SFMCs (fig 4), whereas PAD2 protein could only be detected in significant amounts in the SFMCs (fig 5). These patterns of expression are thus identical to the patterns observed in ex vivo differentiated cells (figs 2 and 3). PAD2 mRNA expression remains unaltered during infiltration of circulating monocytes into the synovium and subsequent differentiation into macrophages. Because PAD2 protein is only expressed in the cells from the SF it appears that translation of its messenger RNA is initiated during macrophage differentiation.

The situation for PAD4 is also identical to the observations made with the ex vivo differentiated cells (figs 2 and 3). PAD4 mRNA could only be detected in the PBMCs (fig 4). PAD4 protein could be detected in similar amounts in the PBMC and SFMC fractions (fig 5). The PAD4 mRNA is thus gradually lost during synovial infiltration and subsequent macrophage differentiation; notwithstanding that the PAD4 protein levels remain unchanged. These results show again that the PAD4 protein that is already present in the $\mathrm{PB}$ monocytes is not degraded during monocyte infiltration and differentiation in the synovium.

\section{PAD2 translation is regulated by its $3^{\prime}$ UTR}

Although monocytes contained comparable amounts of PAD2 mRNA as macrophages or SFMCs, they contained little, if any, PAD2 protein. It thus appears that the PAD2 mRNA is not translated in monocytes and that translation is initiated somewhere during macrophage differentiation.

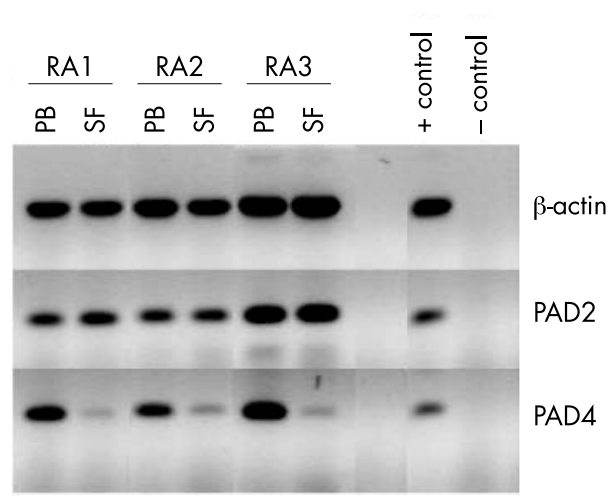

Figure 4 PAD4 mRNA is only present in PBMCs, not in SFMCs. Mononuclear cells were isolated from PB and SF samples of patients with RA. RNA expression of PAD2 and PAD4 was analysed by RT-PCR. $\beta$ Actin served as a control for mRNA input. Cloned cDNAs served as positive PCR controls, (no positive control included for $\beta$-actin), PCR without template as negative control. 

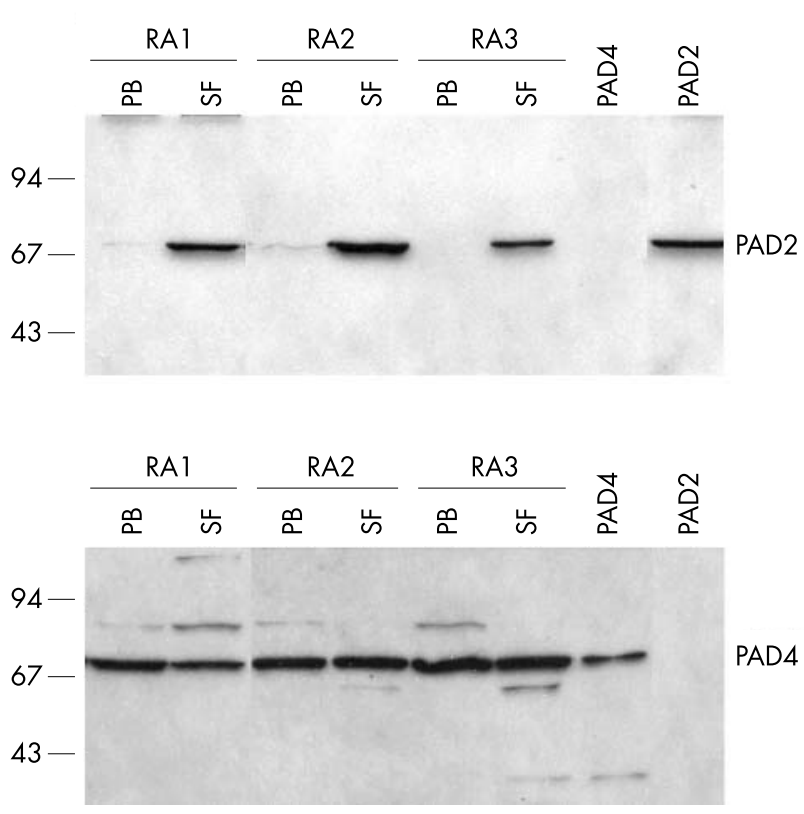

Figure 5 PAD2 protein is only expressed in SFMCs. Protein expression of PAD2 and PAD4 in mononuclear cells isolated from PB and SF samples of patients with RA was analysed by western blotting. Recombinant PAD2 and PAD4 proteins are included as controls. Molecular weight markers $(\mathrm{kDa})$ are indicated on the left.

PAD2 is encoded by a $4.5 \mathrm{~kb}$ transcript (AB023211), ${ }^{41} 42$ which contains a very long $3^{\prime}$ UTR $(>2 \mathrm{~kb})$. To investigate if this $3^{\prime}$ UTR might be involved in regulation of PAD2 expression at the translational level, we cloned the PAD2 3' UTR behind a luciferase reporter gene. Constructs containing firefly luciferase with or without PAD2 3' UTR were transfected into COS-1 cells. A plasmid containing renilla luciferase was cotransfected as a transfection control.

Mean luciferase activity (ratio of firefly to renilla luciferase activity) without PAD2 $3^{\prime}$ UTR was set to $100 \%( \pm 10.3)$. Addition of the PAD2 3' UTR caused a sixfold reduction of luciferase activity $(16.3 \pm 2.0 \%)$. This and the observed expression patterns, indicate that the 3' UTR sequence is important in regulating $\mathrm{PAD} 2$ protein expression at the translational level.

\section{Citrullinated proteins are only generated after calcium influx}

For detection of citrullinated proteins in protein extracts or fixed cells, Senshu and coworkers developed a method in which the citrulline side chain is specifically modified into an artificial amino acid side chain that is so bulky that the influence of flanking amino acids for epitope recognition becomes negligible. ${ }^{39} 434$ We used these antiMC antibodies to detect citrullinated proteins in freshly isolated monocytes and ex vivo differentiated macrophages. Figure 6 (lanes indicated with 0 ) shows that no citrullinated proteins could be detected in either the monocytes or the macrophages.

It thus appears that the mere presence of PAD enzymes in both monocytes (PAD4) and macrophages (PAD2 and PAD4) is not sufficient for the citrullination of intracellular proteins. It is known, however, that calcium ions, and possibly other factors, are required for activity of the PAD enzymes. The threshold $\mathrm{Ca}^{2+}$ concentration for PAD activity is about
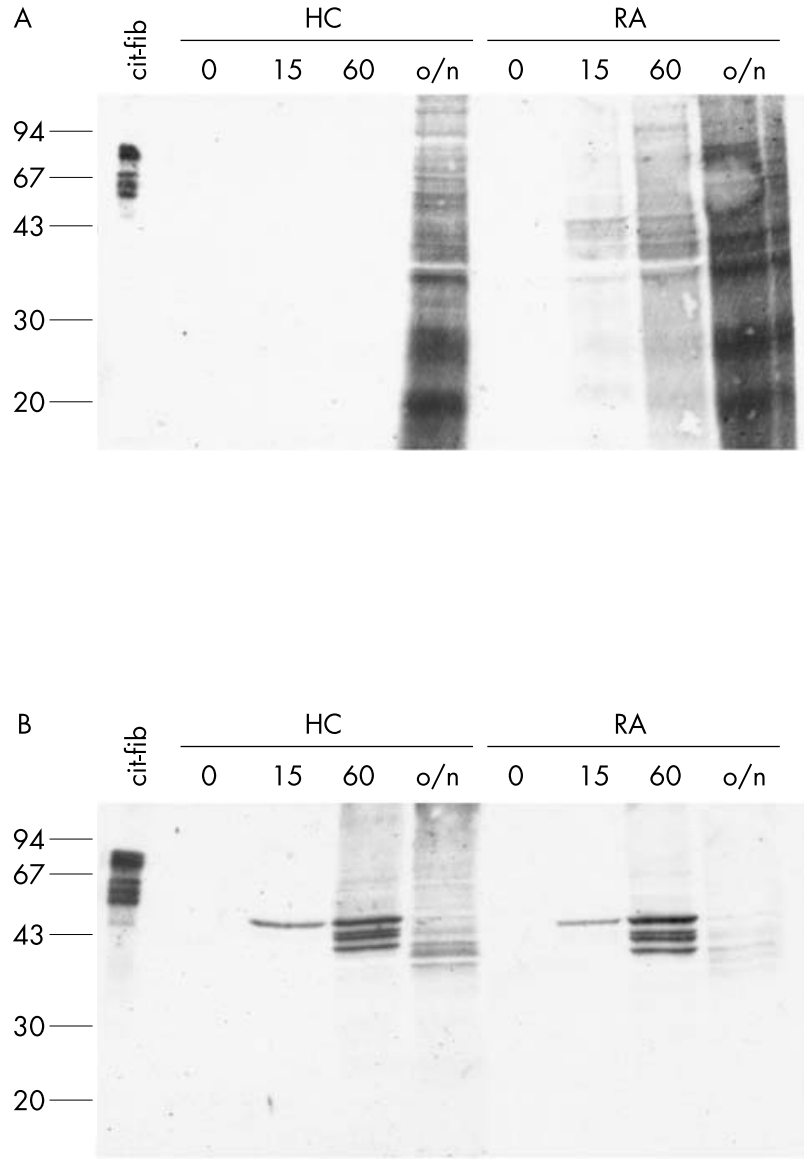

Figure 6 Citrullinated proteins are only generated after calcium influx. Monocytes (A) and macrophages (B) from a healthy control (HC) and a patient with RA were treated for 0,15 minutes, 60 minutes, or overnight $(\mathrm{o} / \mathrm{n})$ with $1 \mu \mathrm{M}$ ionomycin in the presence of $2 \mathrm{mM} \mathrm{CaCl} 2$. Extracts were analysed for the presence of citrullinated proteins by western blotting with anti-MC antibodies. In vitro citrullinated human fibrinogen $(25 \mathrm{ng})$ is included as a positive control. Molecular weight markers (kDa) are indicated on the left.

$10^{-5} \mathrm{~mol} / \mathrm{l}$ (Nijenhuis S, Nijmegen, The Netherlands, personal communication $)^{45}$; the cytosolic calcium concentration in normal cells is much lower $\left(10^{-7} \mathrm{~mol} / \mathrm{l}\right)$. The cytosolic calcium concentration can be artificially raised by addition of various agents like ionomycin or thapsigargin. Ionomycin is a calcium ionophore which facilitates the sustained influx of extracellular calcium. Thapsigargin is an inhibitor of the ubiquitous sarco-endoplasmic reticulum $\mathrm{Ca}^{2+}$-ATPases causing release of calcium from the intracellular $\mathrm{Ca}^{2+}$ stores into the cytosol. ${ }^{46}$ Monocytes and ex vivo differentiated macrophages were therefore treated with $1 \mu \mathrm{M}$ ionomycin or $1 \mu \mathrm{M}$ thapsigargin in the presence of $2 \mathrm{mM}$ extracellular calcium for different periods of time (15 minutes, 60 minutes, or overnight).

As expected, proteins are citrullinated upon ionomycin treatment (fig 6). In macrophages (fig 6B), several distinct bands of citrullinated proteins could be detected. After overnight ( $\sim 18$ hours $)$ treatment with ionomycin, the intensity of the staining decreased and the bands appeared to shift to a lower molecular weight, indicating that the citrullinated proteins are degraded. In monocytes (fig 6A), proteins are citrullinated more slowly than in macrophages (fig 6B). Also different proteins appear to be citrullinated. No differences were seen between cells from patients with RA 
and healthy controls. Citrullination of intracellular proteins was also observed after treatment with thapsigargin (data not shown).

\section{Citrullinated proteins can be immunoprecipitated by antivimentin antibodies}

The four bands that are detectable in the macrophages after 60 minutes of ionomycin treatment are in the molecular weight range of the intermediate filament protein vimentin and the observed banding pattern resembles the banding pattern observed with antivimentin (RV202) monoclonal antibodies (data not shown). Specific citrullination of vimentin during calcium ionophore-induced apoptosis in mouse peritoneal macrophages has been reported previously. ${ }^{35}$ To investigate if indeed vimentin is the citrullinated protein observed after ionomycin treatment, we immunoprecipitated vimentin from ionomycin treated cell extracts. Immunoblots containing immunoprecipitated vimentin were subsequently stained with anti-MC antibodies (fig 7). No citrullinated vimentin could be detected in untreated cells (lanes labelled 0). In monocytes (fig 7A), citrullinated vimentin or its degradation products were detectable after overnight treatment with ionomycin. In contrast, citrullinated vimentin was already detectable in macrophages after
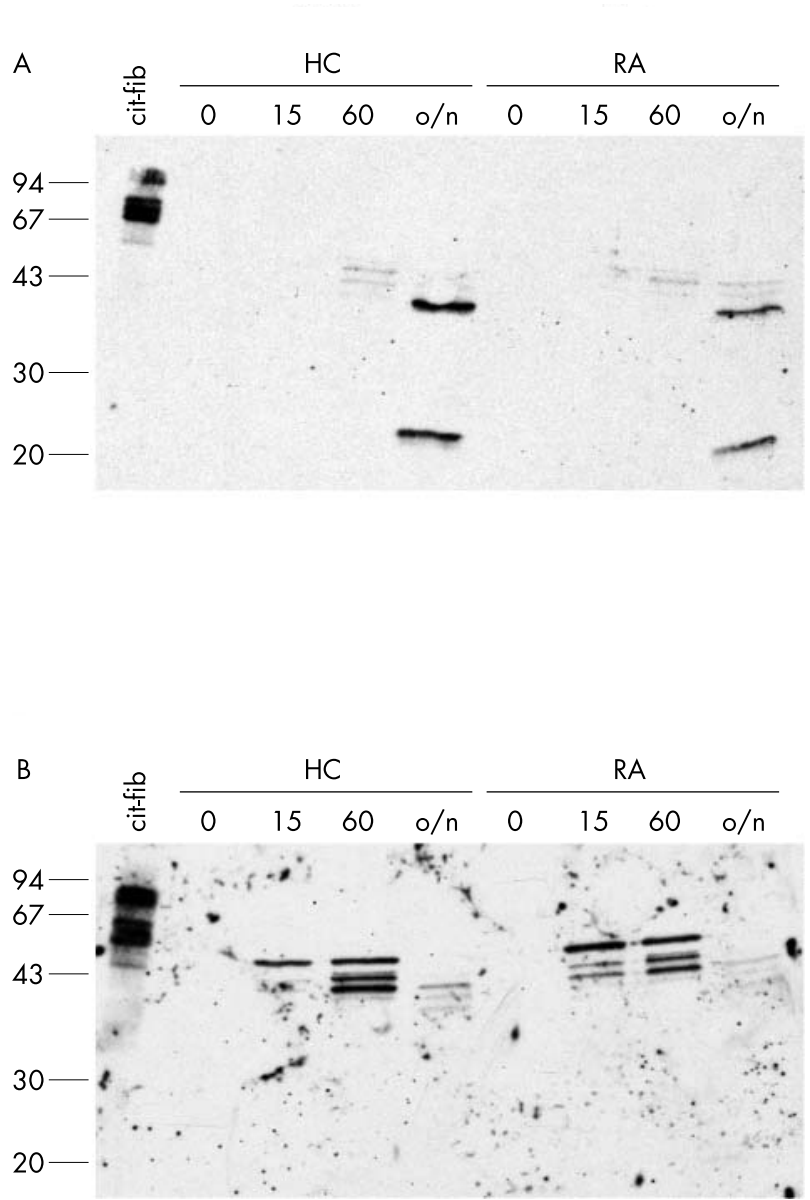

Figure 7 Vimentin is specifically citrullinated in calcium stimulated macrophages. Immunoprecipitated vimentin from monocytes $(A)$ and macrophages (B) from a healthy control $(\mathrm{HC})$ and a patient with RA, treated for 0,15 minutes, 60 minutes, or overnight $(0 / n)$ with $1 \mu M$ ionomycin in the presence of $2 \mathrm{mM} \mathrm{CaCl}$, was stained with anti-MC antibodies. In vitro citrullinated human fibrinogen $(25 \mathrm{ng})$ is included on the western blot as a positive control. Molecular weight markers (kDa) are indicated on the left.
15 minutes of ionomycin treatment (fig 7B). In the macrophages that were treated overnight, only degradation products of citrullinated vimentin could be detected. Analysis of cells from patients with RA and healthy controls gave identical results.

\section{DISCUSSION}

We investigated the expression of four PAD isotypes in PBMCs: PADl to PAD4. The human PAD4 was previously known as PAD5 because it showed slightly different reaction kinetics towards artificial substrates than the rodent PAD4 enzymes. ${ }^{31}$ Sequence data, expression data, intracellular localisation, and the genomic organisation of the PAD genes, ${ }^{23}$ however, all indicate that human PAD5 corresponds to the rodent PAD4. ${ }^{32}{ }^{33}$ Our suggestion to rename the human PAD5 to PAD4 was recently approved by the HUGO Gene Nomenclature Committee..$^{23}$

The most noticeable difference between the different PAD isotypes is their tissue-specific expression (reviewed by Vossenaar $e t \mathrm{al}^{23}$ ). PADl and PAD3 are expressed mainly in epidermis and hair follicles. ${ }^{23-27}$ It is therefore not surprising that their respective mRNAs were undetectable in PBMCs. Expression of PAD2 and PAD4 has been reported in a variety of tissues, including haematopoietic cells. ${ }^{23-33}$ In the

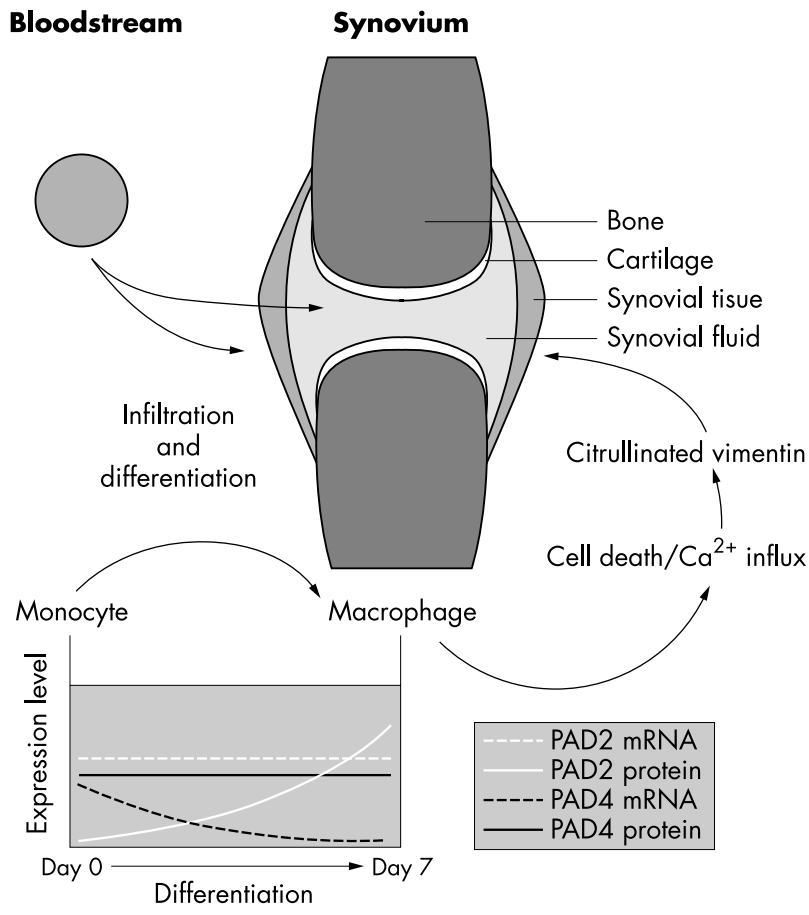

Figure 8 Model for synovial PAD infiltration. Many leucocytes infiltrate the inflamed synovium in RA. When monocytes from the PB enter the synovium, they will differentiate into macrophages. This differentiation process has several consequences for PAD expression: the mRNA expression of PAD4 is lost during differentiation, but the PAD4 protein levels remain unchanged, indicating that the enzyme is not rapidly degraded. For PAD2, the situation is different: the mRNA levels remain more or less the same, but the mRNA is only translated into PAD2 protein in the macrophages. The patterns of PAD expression are identical in patients with RA and healthy controls, but because of the large numbers of macrophages that can be found in the RA (and not in healthy) synovium, the amount of PAD enzyme in the RA synovium will be much higher than in healthy synovium. During apoptosis or necrosis of the PAD-containing macrophages, free intracellular $\mathrm{Ca}^{2+}$ levels are increased, resulting in activation of the PAD enzymes and citrullination of cellular proteins. In the macrophages, vimentin is specifically citrullinated after increase of cytoplasmic $\mathrm{Ca}^{2+}$. Furthermore, PAD enzymes may leak out of necrotic cells, causing the citrullination of extracellular proteins (for example, fibrin ${ }^{21}$ ). 
PMBCs, both PAD2 and PAD4 mRNA were predominantly expressed in the monocytes (CD14+, CD3-, CD19-, CD56cells).

Differentiation of the monocytes into macrophages (both ex vivo and in vivo) has several consequences for PAD expression (summarised in fig 8). The mRNA expression of PAD4 is lost during differentiation. Nevertheless, the PAD4 protein levels remain unchanged, indicating that the enzyme is stable and not degraded. In contrast, PAD2 mRNA levels remain unchanged, while $\mathrm{PAD} 2$ protein levels significantly increase during differentiation. It appears that the translation of PAD2 mRNA is blocked in the monocytes. This apparent discrepancy has previously been described in epidermis; although PAD2 mRNA was found in the epidermis, ${ }^{47}$ PAD2 protein was absent. ${ }^{48}$

Expression of many proteins is regulated post-transcriptionally by 5' and 3' UTR motifs. The 5' UTR of PAD2 is only $64 \mathrm{nts}$ in length, in contrast, the $3^{\prime}$ UTR measures $2.3 \mathrm{~kb}$. PAD4, in contrast, contains a much shorter 3' UTR of 245 nts. By cloning the very long 3' UTR of PAD2 behind a luciferase reporter gene, we showed that the $3^{\prime}$ UTR is responsible for inhibition of translation, as luciferase activity was reduced over sixfold by the PAD2 3' UTR. Most, if not all, mRNAs regulated by $3^{\prime}$ UTR motifs are subjected to regulation during early embryonic development or during differentiation (reviewed by Standart and Jackson ${ }^{49}$ ). Examples of such differentially regulated mRNAs are protamines in developing sperm cells ${ }^{50}$ and 15-lipoxygenase during erythroid differentiation. ${ }^{51}{ }^{52}$ A general mechanism for post-transcriptional regulation by $3^{\prime}$ motifs is the binding of regulatory proteins to specific differentiation control elements in the $3^{\prime}$ UTR region of the mRNA. ${ }^{49}$ These regulatory proteins interact with the $5^{\prime}$ end of the mRNA by forming a loop structure. In this way they prevent the binding of initiation factors to the mRNA. ${ }^{53}$ Which parts of the $3^{\prime}$ UTR of PAD2 and which regulatory proteins are involved in the observed cell stage-specific inhibition of translation, is currently under investigation.

Although PAD enzymes were present in monocytes (PAD4) and macrophages (PAD2 and PAD4), they apparently were not active, because no citrullinated proteins were detectable. The cytosolic and nucleoplasmic $\mathrm{Ca}^{2+}$ concentration under normal physiological conditions is much too low (about 100fold) for PAD activity. ${ }^{45}$ Raising the cytosolic and nucleoplasmic calcium concentration by treatment with either ionomycin or thapsigargin induced activation of PAD and subsequent citrullination of intracellular proteins. As shown in fig 6, monocytes and macrophages had different banding patterns of citrullinated proteins. PAD activation by treatment with a calcium ionophore has been described previously for mouse macrophages,,$^{35}$ rat keratinocytes, ${ }^{36}$ and human HL60 granulocytes. ${ }^{33}{ }^{54} \mathrm{~A}$ rise in cytosolic $\mathrm{Ca}^{2+}$ levels is important for induction of apoptosis. ${ }^{55}{ }^{56}$ During apoptosis (or necrosis) the plasma membrane $\mathrm{Ca}^{2+}$ pump (PMCA) is cleaved by caspases, so that influxing calcium can no longer be efficiently cleared by PMCA, which results in $\mathrm{Ca}^{2+}$ overload. ${ }^{57}$ This may explain why citrullination in vivo takes place during death or terminal differentiation of cells (for example, citrullination of filaggrin and keratin during terminal differentiation of keratinocytes ${ }^{43559}$ ), when control of calcium homoeostasis is lost.

Vimentin is specifically citrullinated in the macrophages after $\mathrm{Ca}^{2+}$ influx. This observation has previously been reported for mouse peritoneal macrophages, ${ }^{35}$ although no suggestions were made at that time about which PAD isotype is responsible for vimentin citrullination. We show here that macrophages contain both PAD2 and PAD4, the former is located in the cytosol, the latter in the nucleus. ${ }^{33}$ Vimentin is an intermediate filament protein and thus is located in the cytosol. This makes PAD2 the most likely candidate for vimentin citrullination. The high cytosolic $\mathrm{Ca}^{2+}$ levels in the ionomycin treated monocytes and macrophages induce cell death, ${ }^{35} 55$ which leads to nuclear fragmentation and subsequent release of PAD4 into the cytosol. This may explain why vimentin is citrullinated much more slowly in monocytes, which only contain PAD4 protein (fig 7).

After overnight exposure to high cytosolic $\mathrm{Ca}^{2+}$, citrullinated vimentin was shown to be degraded. In healthy cells, the vimentin cytoskeleton is a highly dynamic structure, as polymerisation and depolymerisation of the filaments are involved in various biological functions. Under physiological conditions, these processes are regulated by reversible phosphorylation at specific sites in the amino terminal head domain of the vimentin molecules. ${ }^{60}$ In apoptotic cells, the network of vimentin filaments is disrupted; it collapses into perinuclear aggregates. Two processes may contribute to this collapse. Citrullination of the amino terminal head domain by PAD induces disassembly of the vimentin filaments. ${ }^{61}$ Furthermore, vimentin is subjected to cleavage by caspases early in apoptosis. ${ }^{62-64}$ Although no data exist on a possible correlation between these two processes in this specific case, in general, citrullination of proteins causes protein unfolding, which makes them more susceptible to proteolysis. ${ }^{23}{ }^{65-67}$

Figure 8 shows a schematic representation of the events that may lead to the production of citrullinated vimentin in the inflamed synovium. Monocytes are recruited to the inflamed synovium by various chemoattractant factors. After infiltration of the synovium, monocytes will differentiate into macrophages, which causes up regulation of PAD2 protein and down regulation of PAD4 mRNA expression.

The macrophages that are abundantly present in the RA synovial tissue (in RA $80-100 \%$ of synovial lining cells are macrophage-like cells, compared with $20-30 \%$ in normal synovium $^{34}$ ) show signs of activation. ${ }^{68}$ Short term activated macrophages are protected from apoptosis, whereas long term ( $>24$ hours) activated macrophages are very prone to cell death.$^{69}$ Calcium influx in the dying macrophages triggers activation of PAD and subsequent citrullination of vimentin. Furthermore, PAD enzymes may leak out of dead cells, enabling them to citrullinate extracellular proteins, like fibrin..$^{21} 70$ The likely presence of citrullinated vimentin in the rheumatoid synovium, makes it a potential autoantigen in RA. Interestingly, antibodies directed to the Sa antigen (which might be citrullinated vimentin ${ }^{71}$ ) are highly specific for RA and can be detected in about $50 \%$ of patients with RA. $^{72}$

In conclusion, our data show that citrullination of proteins by $\mathrm{PAD}$ enzymes is a process regulated at three levels: transcription, translation, and activation (by $\mathrm{Ca}^{2+}$ influx). Vimentin is specifically citrullinated by macrophages after $\mathrm{Ca}^{2+}$ influx and citrullinated vimentin is a candidate autoantigen in RA. PAD2 and PAD4 are the most likely candidate $\mathrm{PAD}$ isotypes for the citrullination of synovial proteins in RA.

\section{ACKNOWLEDGEMENTS}

We thank Dr Tatsuo Senshu (Tokyo, Japan) for providing antibodies directed against chemically modified peptidylcitrulline, Suzanne Nijenhuis (Nijmegen, The Netherlands) for providing purified recombinant human PAD2 and PAD4 protein, Drs Ger Pruijn and Reinout Raijmakers (Nijmegen, The Netherlands) for useful discussion and assistance, and Dr Rob Moots (Liverpool, UK) and his staff for help in optimising the RT-PCR procedures. This work would have been impossible without the generous blood donations of all participating patients with RA and healthy subjects.

This work was financially supported by the Netherlands Foundation for Chemical Research and the Netherlands Technology Foundation (grant 349-5077), Het Nationaal Reumafonds of The Netherlands (the Dutch League against Rheumatism, grant 00-2-402), and the Netherlands Foundation for Medical Research (NWO grant 940-35037). 


\section{Authors' affiliations}

E R Vossenaar, A van der Heijden, M A M van Mansum, C Dieteren, A J W Zendman, W J van Venrooii, Department of Biochemistry, University of Nijmegen, Nijmegen, The Netherlands

T R D Radstake, P Barrera, Department of Rheumatology, University Medical Centre, St Radboud, Nijmegen, The Netherlands

D-J de Rooij, Department of Rheumatology, Sint Maartenskliniek, Nijmegen, The Netherlands

\section{REFERENCES}

1 Mageed RA. The RF antigen. In: van Venrooij WJ, Maini RN, eds. Manual of biological markers of disease. Dordrecht, The Netherlands: Kluwer Academic Publishers, 1996; Section B1.1:1-27.

2 Lisse JR. Does rheumatoid factor always mean arthritis? Postgrad Med 1993:94:133-4, 139.

3 van Boekel MA, Vossenaar ER, van den Hoogen FH, van Venrooij WJ. Autoantibody systems in rheumatoid arthritis: specificity, sensitivity and diagnostic value. Arthritis Res 2002;4:87-93.

4 Nienhuis RLF, Mandema EA. A new serum factor in patients with rheumatoid arthritis. The antiperinuclear factor. Ann Rheum Dis 1964;23:302-5.

5 Young BJ, Mallya RK, Leslie RD, Clark CJ, Hamblin TJ. Anti-keratin antibodies in rheumatoid arthritis. BMJ 1979:ii:97-9.

6 Simon M, Girbal E, Sebbag M, Gomes DV, Vincent C, Salama, et al. The cytokeratin filament-aggregating protein filaggrin is the target of the so-called "antikeratin antibodies," autoantibodies specific for rheumatoid arthritis. J Clin Invest 1993;92:1387-93.

7 Sebbag M, Simon M, Vincent C, Masson BC, Girbal E, Durieux JJ, et al. The antiperinuclear factor and the so-called antikeratin antibodies are the same rheumatoid arthritis-specific autoantibodies. J Clin Invest 1995;95:2672-9.

8 Schellekens GA, de Jong BA, van den Hoogen FH, van de Putte LB, van Venrooij WJ. Citrulline is an essential constituent of antigenic determinants recognized by rheumatoid arthritis-specific autoantibodies. J Clin Invest 1998; 101:273-81.

9 Schellekens GA, Visser $H$, de Jong BA, van den Hoogen FH, Hazes JM, Breedveld FC, et al. The diagnostic properties of rheumatoid arthritis antibodies recognizing a cyclic citrullinated peptide. Arthritis Rheum 2000;43:155-63.

10 van Venrooij WJ, Hazes JM, Visser H. Anticitrullinated protein/peptide antibody and its role in the diagnosis and prognosis of early rheumatoid arthritis. Neth J Med 2002;60:383-8.

11 Vasishta A. Diagnosing early-onset rheumatoid arthritis: the role of anti-CCP antibodies. Am Clin Lab 2002;21:34-6.

12 Bizzaro N, Mazzanti G, Tonutti E, Villalta D, Tozzoli R. Diagnostic accuracy of the anti-citrulline antibody assay for rheumatoid arthritis. Clin Chem 2001;47:1089-93.

13 Palosuo T, Tilvis R, Strandberg T, Aho K. Filaggrin related antibodies among the aged. Ann Rheum Dis 2003:62:261-3.

14 Visser H, Le Cessie S, Vos K, Breedveld FC, Hazes JM. How to diagnose rheumatoid arthritis early? A prediction model for persistent (erosive) arthritis. Arthritis Rheum 2002;46:357-65

15 Kroot EJ, de Jong BA, van Leeuwen MA, Swinkels $H$, van den Hoogen FH, van't Hof $M$, et al. The prognostic value of anti-cyclic citrullinated peptide antibody in patients with recent-onset rheumatoid arthritis. Arthritis Rheum 2000;43:1831-5

16 Meyer O, Labarre C, Dougados M, Goupille P, Cantagrel A, Dubois A, et al. Anticitrullinated protein/peptide antibody assays in early rheumatoid arthritis for predicting five year radiographic damage. Ann Rheum Dis 2003;62:120-6.

17 Vencovsky J, Machacek S, Sedova L, Kafkova J, Gatterova J, Pesakova V, et al. Autoantibodies can be prognostic markers of an erosive disease in early rheumatoid arthritis. Ann Rheum Dis 2003:62:427-30.

18 Smeets TJ, Vossenaar ER, Kraan MC, Van Mansum WAM, Raats JM, van Venrooij WJ, et al. Expression of citrulline-containing antigens in RA synovium [abstract]. Arthritis Res 2002;3:P4

19 Masson-Bessière C, Sebbag M, Durieux JJ, Nogueira L, Vincent C, Girbal-

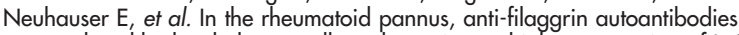
are produced by local plasma cells and constitute a higher proportion of IgG than in synovial fluid and serum. Clin Exp Immunol 2000; 1 19:544-52.

20 Reparon-Schuijt CC, van Esch WJ, van Kooten C, Schellekens GA, de Jong BA, van Venrooij WJ, et al. Secretion of anti-citrulline-containing peptide antibody by B lymphocytes in rheumatoid arthritis. Arthritis Rheum 2001;44:41-7.

21 Masson-Bessière C, Sebbag M, Girbal-Neuhauser E, Nogueira L, Vincent C, Senshu T, et al. The major synovial targets of the rheumatoid arthritis-specific antifilaggrin autoantibodies are deiminated forms of the alpha- and betachains of fibrin. J Immunol 2001; 166:4177-84.

22 van Venrooij WJ, Pruijn GJ. Citrullination: a small change for a protein with great consequences for rheumatoid arthritis. Arthritis Res 2000;2:249-51.

23 Vossenaar ER, Zendman AJW, van Venrooij WJ, Pruijn G PAD. A growing family of citrullinating enzymes: genes, features and involvement in disease. Bioessays, 2003:25:1106-18.

24 Rus'd AA, lkejiri Y, Ono H, Yonekawa T, Shiraiwa M, Kawada A, et al. Molecular cloning of cDNAs of mouse peptidylarginine deiminase type I, type III and type IV, and the expression pattern of type I in mouse. Eur J Biochem 1999;259:660-9.

25 Rogers G, Winter B, McLaughlan C, Powell B, Nesci A. Hair follicle peptidylarginine deiminase. Exp Dermatal 1992;8:362-3.
26 Kanno T, Kawada A, Yamanouchi J, Yosida-Noro C, Yoshiki A, Shiraiwa M, et al. Human peptidylarginine deiminase type III: molecular cloning and nucleotide sequence of the cDNA, properties of the recombinant enzyme, and immunohistochemical localization in human skin. J Invest Dermatol 2000;115:813-23.

27 Guerrin M, Ishigami A, Mechin MC, Nachat R, Valmary S, Sebbag M, et al. cDNA cloning, gene organization and expression analysis of human peptidylarginine deiminase type I. Biochem J 2003;370:167-74.

28 Watanabe K, Akiyama K, Hikichi K, Ohtsuka R, Okuyama A, Senshu T. Combined biochemical and immunochemical comparison of peptidylarginine deiminases present in various tissues. Biochim Biophys Acta 1988;966:375-83.

29 Nagata S, Senshu T. Peptidylarginine deiminase in rat and mouse hemopoietic cells. Experientia 1990:46:72-4.

30 Ishigami A, Ohsawa T, Asaga H, Akiyama K, Kuramoto M, Maruyama N Human peptidylarginine deiminase type II: molecular cloning, gene organization, and expression in human skin. Arch Biochem Biophys 2002;407:25.

31 Nakashima K, Hagiwara T, Ishigami A, Nagata S, Asaga H, Kuramoto M, et al. Molecular characterization of peptidylarginine deiminase in $\mathrm{HL}-60$ cells induced by retinoic acid and lalpha,25-dihydroxyvitamin $\mathrm{D}(3)$. J Biol Chem 1999;274:27786-92.

32 Asaga H, Nakashima K, Senshu T, Ishigami A, Yamada M. Immunocytochemical localization of peptidylarginine deiminase in human eosinophils and neutrophils. J Leukoc Biol 2001;70:46-51

33 Nakashima K, Hagiwara T, Yamada M. Nuclear localization of peptidylarginine deiminase $\mathrm{V}$ and histone deimination in granulocytes. J Biol Chem 2002;277:49562-8.

34 Cutolo M, Sulli A, Barone A, Seriolo B, Accardo S. Macrophages, synovial tissue and rheumatoid arthritis. Clin Exp Rheumatol 1993; 1 1:331-9.

35 Asaga H, Yamada M, Senshu T. Selective deimination of vimentin in calcium ionophore-induced apoptosis of mouse peritoneal macrophages. Biochem Biophys Res Commun 1998;243:641-6.

36 Mizoguchi M, Manabe M, Kawamura Y, Kondo Y, Ishidoh K, Kominami, et al. Deimination of $70-k D$ nuclear protein during epidermal apoptotic events in vitro. J Histochem Cytochem 1998:46:1303-9.

37 Arnett FC, Edworthy SM, Bloch DA, McShane DJ, Fries JF, Cooper NS, et al. The American Rheumatism Association 1987 revised criteria for the classification of rheumatoid arthritis. Arthritis Rheum 1988;31:315-24

38 Rodenburg RJ, van den Hoogen FH, van de Putte LB, van Venrooii WJ. Peripheral blood monocytes of rheumatoid arthritis patients do not express elevated TNF alpha, IL-1 beta, and IL-8 mRNA levels. A comparison of monocyte isolation procedures. J Immunol Methods 1998;221:169-75.

39 Senshu T, Sato T, Inoue T, Akiyama K, Asaga H. Detection of citrulline residues in deiminated proteins on polyvinylidene difluoride membrane. Anal Biochem 1992;203:94-100.

40 Kikuno R, Nagase T, Waki M, Ohara O. HUGE: a database for human large proteins identified in the Kazusa cDNA sequencing project. Nucleic Acids Res 2002;30:166-8.

41 Watanabe K, Senshu T. Isolation and characterization of CDNA clones encoding rat skeletal muscle peptidylarginine deiminase. J Biol Chem 1989;264:15255-60

42 Tsuchida M, Takahara H, Minami N, Arai T, Kobayashi Y, Tsujimoto H, et al. cDNA nucleotide sequence and primary structure of mouse uterine peptidylarginine deiminase. Detection of a 3 '-untranslated nucleotide sequence common to the mRNA of transiently expressed genes and rapid turnover of this enzyme's mRNA in the estrous cycle. Eur J Biochem 1993; 215:677-85.

43 Senshu T, Akiyama K, Kan S, Asaga H, Ishigami A, Manabe M. Detection of deiminated proteins in rat skin: probing with a monospecific antibody after modification of citrulline residues. J Invest Dermatol 1995;105:163-9.

44 Asaga H, Senshu T. Combined biochemical and immunocytochemical analyses of postmortem protein deimination in the rat spinal cord. Cell Biol Int 1993; 17:525-32.

45 Takahara H, Okamoto-H, Sugawara K. Calcium-dependent properties of peptidylarginine deiminase from rabbit skeletal muscle. Agric Biol Chem 1986;50:2899-904.

46 Treiman M, Caspersen C, Christensen SB. A tool coming of age: thapsigargin as an inhibitor of sarco-endoplasmic reticulum $\mathrm{Ca}(2+)$-ATPases. Trends Pharmacol Sci 1998;19:131-5.

47 Ishigami A, Asaga H, Ohsawa T, Akiyama K, Maruyama N. Peptidylarginine deiminase type I, type II, type II and type IV are expressed in rat epidermis. Biomed Res 2001 :22:63-5.

48 Urano Y, Watanabe K, Sakaki A, Arase S, Watanabe Y, Shigemi F, et al. Immunohistochemical demonstration of peptidylarginine deiminase in human sweat glands. Am J Dermatopathol 1990;12:249-55.

49 Standart N, Jackson RJ. Regulation of translation by specific protein/mRNA interactions. Biochimie 1994;76:867-79.

50 Steger K. Haploid spermatids exhibit translationally repressed mRNAs. Anat Embryol (Berl) 2001;203:323-34.

51 Ostareck DH, Ostareck-Lederer A, Wilm M, Thiele BJ, Mann M, Hentze MW. mRNA silencing in erythroid differentiation: hnRNP K and hnRNP El regulate 15-lipoxygenase translation from the $3^{\prime}$ end. Cell 1997;89:597-606.

52 Ostareck DH, Ostareck-Lederer A, Shatsky IN, Hentze MW. Lipoxygenase mRNA silencing in erythroid differentiation: The 3'UTR regulatory complex controls 60S ribosomal subunit joining. Cell 2001;104:281-90.

53 Mazumder B, Seshadri V, Fox PL. Translational control by the 3'-UTR: the ends specify the means. Trends Biochem Sci 2003;28:91-8.

54 Hagiwara T, Nakashima K, Hirano H, Senshu T, Yamada M. Deimination of arginine residues in nucleophosmin/B23 and histones in $\mathrm{HL}-60$ granulocytes. Biochem Biophys Res Commun 2002;290:979-83. 
55 Tombal B, Denmeade SR, Gillis JM, Isaacs JT. A supramicromolar elevation of intracellular free calcium $([\mathrm{Ca}(2+)](i))$ is consistently required to induce the execution phase of apoptosis. Cell Death Differ 2002;9:561-73.

56 Sasamura S, Furukawa K, Shiratori M, Motomura S, Ohizumi Y. Antisenseinhibition of plasma membrane $\mathrm{Ca}(2+)$ pump induces apoptosis in vascular smooth muscle cells. Jpn J Pharmacol 2002;90:164-72.

57 Schwab BL, Guerini D, Didszun C, Bano D, Ferrando-May E, Fava E, et al Cleavage of plasma membrane calcium pumps by caspases: a link between apoptosis and necrosis. Cell Death Differ 2002;9:818-31.

58 Senshu T, Kan S, Ogawa H, Manabe M, Asaga H. Preferential deimination of keratin $\mathrm{K} 1$ and filaggrin during the terminal differentiation of human epidermis. Biochem Biophys Res Commun 1996;225:712-19.

59 Senshu T, Akiyama K, Nomura K. Identification of citrulline residues in the $\mathrm{V}$ subdomains of keratin $\mathrm{K} 1$ derived from the cornified layer of newborn mouse epidermis. Exp Dermatol 1999;8:392-401.

60 Inagaki M, Nishi Y, Nishizawa K, Matsuyama M, Sato C. Site-specific phosphorylation induces disassembly of vimentin filaments in vitro. Nature 1987;328:649-52

61 Inagaki M, Takahara H, Nishi Y, Sugawara K, Sato C. Ca(2+)-dependent deimination-induced disassembly of intermediate filaments involves specific modification of the amino-terminal head domain. J Biol Chem 1989;264:18119-27.

62 Muller K, Dulku S, Hardwick SJ, Skepper JN, Mitchinson MJ. Changes in vimentin in human macrophages during apoptosis induced by oxidised low density lipoprotein. Atherosclerosis 2001;156:133-44.

63 Byun Y, Chen F, Chang R, Trivedi M, Green KJ, Cryns VL. Caspase cleavage of vimentin disrupts intermediate filaments and promotes apoptosis. Cell Death Differ $2001 ; 8: 443-50$
64 Morishima N. Changes in nuclear morphology during apoptosis correlate with vimentin cleavage by different caspases located either upstream or downstream of Bcl-2 action. Genes Cells 1999;4:401-14.

65 Cao L, Goodin R, Wood D, Moscarello MA, Whitaker JN. Rapid release and unusual stability of immunodominant peptide 45-89 from citrullinated myelin basic protein. Biochemistry 1999;38:6157-63.

66 Resing KA, al-Alawi N, Blomquist C, Fleckman P, Dale BA. Independent regulation of two cytoplasmic processing stages of the intermediate filamentassociated protein filaggrin and role of $\mathrm{Ca}(2+)$ in the second stage. J Biol Chem 1993;268:25139-45.

67 Tarcsa E, Marekov LN, Mei G, Melino G, Lee SC, Steinert PM. Protein unfolding by peptidylarginine deiminase. Substrate specificity and structural relationships of the natural substrates trichohyalin and filaggrin. J Biol Chem 1996;271:30709-16

68 Feldmann M, Brennan FM, Maini RN. Rheumatoid arthritis. Cell 1996;85:307-10.

69 Rodenburg RJ, Ganga A, van Lent PL, van de Putte LB, van Venrooij WJ. The antiinflammatory drug sulfasalazine inhibits tumor necrosis factor alpha expression in macrophages by inducing apoptosis. Arthritis Rheum 2000;43:1941-50.

70 Vossenaar ER, Nijenhuis S, van Helsen MM, van der Heijden A, Senshu T, van den Berg WB, et al. Citrullination of synovial proteins in murine models of rheumatoid arthritis. Arthritis Rheum 2003;48:2489-500.

71 Menard HA, Lapointe E, Rochdi MD, Zhou Z. Insights into rheumatoid arthritis derived from the Sa immune system. Arthritis Res 2000;2:429-32.

72 Despres N, Boire G, Lopez LF, Menard HA. The Sa system: a novel antigenantibody system specific for rheumatoid arthritis. J Rheumato 1994;21:1027-33. 